\title{
INVESTIGATION OF MINERAL ALTERATION IN ANDESITE AND DACITE FROM THREE DIFFERENT VOLCANO HYDROTHERMAL SYSTEMS ON DOMINICA, LESSER ANTILLES
}

\author{
CLARISSA ITZEL VILLEGAS SMITH, Carleton College
}

Research Advisors: Cameron Davidson, Holli Frey, and Erouscilla Joseph

\section{INTRODUCTION}

Dominica is geologically similar to the nearby islands of Guadeloupe, Montserrat, and St. Lucia in the Lesser Antilles. Unlike the latter three, a comprehensive study has yet to be conducted on the alteration minerals resulting from the hydrothermal and fumarolic environments on this island. Dominica has nine volcanoes and is primarily composed of andesite and dacite. Four of these volcanic centers are associated with geothermal activity where hot sulfur-bearing gases from magmatic sources mix with meteoric water to produce steam-heated acidic-sulfate waters. One of the geothermal areas, the Cold Soufriere has colder surface temperatures compared to others on the island. The hydrothermal waters of Dominica are classified as acid-sulfate and are immature with respect to bedrock interaction (Joseph et al., 2011; Onlyeali et al., 2017). Immaturity depends on the degree of interaction and mixing that has occurred between the water and the host lithology in the reservoir. Immature waters do not achieve equilibrium with the host rock composition and therefore the use of solute $(\mathrm{Na}, \mathrm{K}$, and $\mathrm{Mg}$ ) geothermometry is not appropriate. Silica thermometry may be a more reasonable option for estimating reservoir temperatures in this case. Silica thermometry of the hydrothermal waters shows that the reservoir temperature of the Cold Soufriere is $<80{ }^{\circ} \mathrm{C}$, whereas Sulfur Springs and the Valley of Desolation have reservoir temperatures of $100-200{ }^{\circ} \mathrm{C}$ (Onlyeali et al., 2017). Rocks in these hydrothermal areas typically are observed with a rind of sublimates and incrustations composed of secondary alteration minerals.
Samples of the altered rock were collected from three different hydrothermal site locations in Dominica, which vary in temperature, as well as moisture level. The aim of this research project is to address the following questions: What minerals are present in the rocks and associated alteration rinds at these sites? What were the processes causing this alteration? Finally, what differences exist between these three sites?

\section{FIELD SITES AND SAMPLE DESCRIPTIONS}

Samples were collected from three hydrothermal areas on the island of Dominica: 1) Valley of Desolation, 2) Sulfur Springs, and 3) Cold Soufriere.

The Valley of Desolation hydrothermal area covers an area of about $0.5 \mathrm{~km}^{2}$ and is characterized by high inputs of surface water and fumarolic gases containing $\mathrm{H}_{2} \mathrm{~S}$ and $\mathrm{CO}_{2}$. Water and gas temperatures range from $69-98^{\circ} \mathrm{C}$ and $\mathrm{pH}$ ranges from $1-4$ (Onlyeali et al., 2017). Alteration rinds are found on andesite and dacite blocks, cobbles and pebbles and vary in thickness from 1-20 mm. Some rinds are well lithified whereas other rinds are poorly lithified and argillitic. The rinds display distinctive colors including white, dark grey, orange, yellow, green, pink, and purple.

The predominantly gaseous hydrothermal site at Sulfur Springs is very dry, with little to no surface water inputs. Temperatures of the gas fumaroles range from 41-97 ${ }^{\circ} \mathrm{C}$ and the $\mathrm{pH}$ range from 1-3. Sulfur Springs covers the largest area out of the three sites. The dominant lithology of this site is rounded andesite cobbles. 
The unaltered cores of the cobbles are grayish white in color with a very well lithified thin white rind that is 3-13 mm thick. In some cases there are two layers of rinds around the unaltered core that are easily separable from each other.

The smallest site, the Cold Soufriere, covers an area of $25 \mathrm{~m}^{2}$. There are significant surface water inputs in the form of several small pools. Temperatures in these water pools range from $18-32{ }^{\circ} \mathrm{C}$ and the $\mathrm{pH}$ from 1-4. The rocks in this area appear to be the most altered of the three sites. Most of the rock samples are argillic and crumble easily, whereas others have harder rinds 2-10 $\mathrm{mm}$ in thickness and pinkish gray cores.

\section{METHODS}

Due to the fine-grained nature of the alteration rinds, we used the Phillips PW-1840 powder X-ray diffractometer at Union College to identify the minerals present in sixteen samples of rock rinds. This was also done for one unaltered rock core from Sulfur Springs. To make powders for XRD analysis, the weathered rind of the rock (Fig. 1) was scraped from the rock surface with a dental pick, then ground into a fine powder using a mortar and pestle. In some cases, multiple powder samples were taken from a single hand sample, separated by differences in alteration colors or by inner vs. outer rind layers.

PANalytical HighScorePlus was used with the Crystallography Open Database (Grazulis et al., 2009) for mineral identification and Rietveld analysis yielded the abundance of each mineral type in a given sample. In addition, we measured the wholerock major and trace element geochemistry of one unaltered core of a rock sample from Valley of Desolation using ICP-OES at Acme Labs and ICP-MS at Union College, respectively.

Thin-sections were prepared to examine the boundary between the alteration rind and unaltered core. X-ray maps and quantitative elemental analyses of the minerals present were done with the Union College Zeiss EVO-MA15 equipped with a Bruker EDX system.

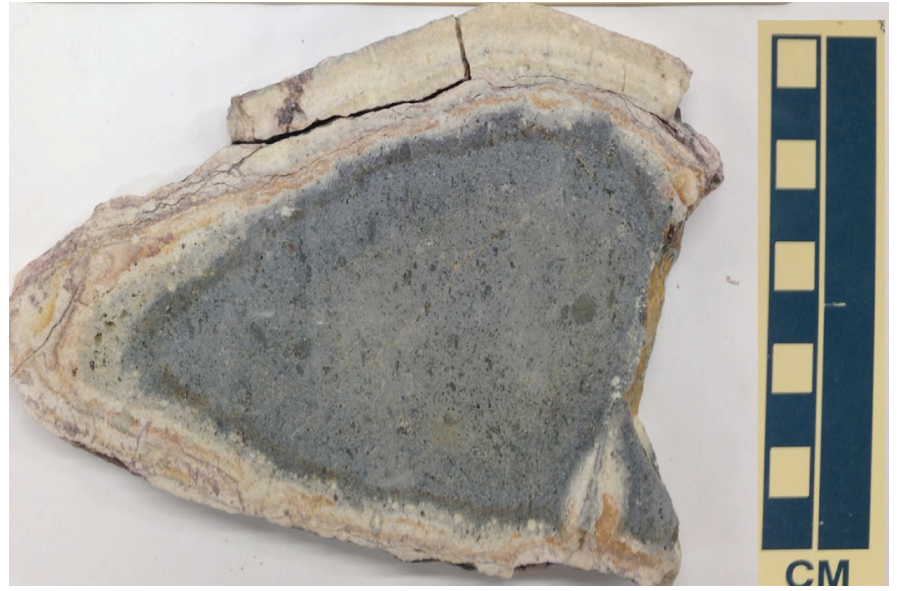

Fig. 1: A cross section of an andesite cobble from the Valley of Desolation showing the well lithified alteration rind characteristic of the area.

\section{RESULTS}

Rietveld analysis of the XRD spectra yielded a total of fifteen different minerals across all the samples (Fig. 2). The types of minerals present include: silica polymorphs, hematite, alunite minerals, sulfates, sulfides, and feldspars. Silica polymorphs are dominant with about $70 \%$ of the samples containing cristobalite, and only one sample, from the Cold Soufriere, contains jarosite, a mineral commonly found in inactive fumaroles on the island of Guadeloupe (Salaün et al., 2011). Alunite, a mineral characteristic of higher temperatures (Aguilera et al., 2016), is present in the Valley of Desolation and Sulfur Springs samples, but it is not present in any Cold Soufriere samples. Six of the altered rinds contain feldspar and no sulfates (Fig. 3).

\section{DISCUSSION}

The minerals across all three sites are typical of rock alteration by low temperature $\left(<300^{\circ} \mathrm{C}\right)$ acid-sulfate fluids, suggesting that the alteration observed is a result of interaction with shallow groundwater and sulfur gases (Joseph et al., 2011). At the Cold Soufriere, the site with the lowest temperatures, there was an absence of the mineral alunite. A hydrous sulfate mineral, alunite was found in the two other field locations. This may be a clue as to how differences in the minerals present for each site may be attributed to distinct hydrothermal systems with different temperatures (Aguilera et al., 2016). 


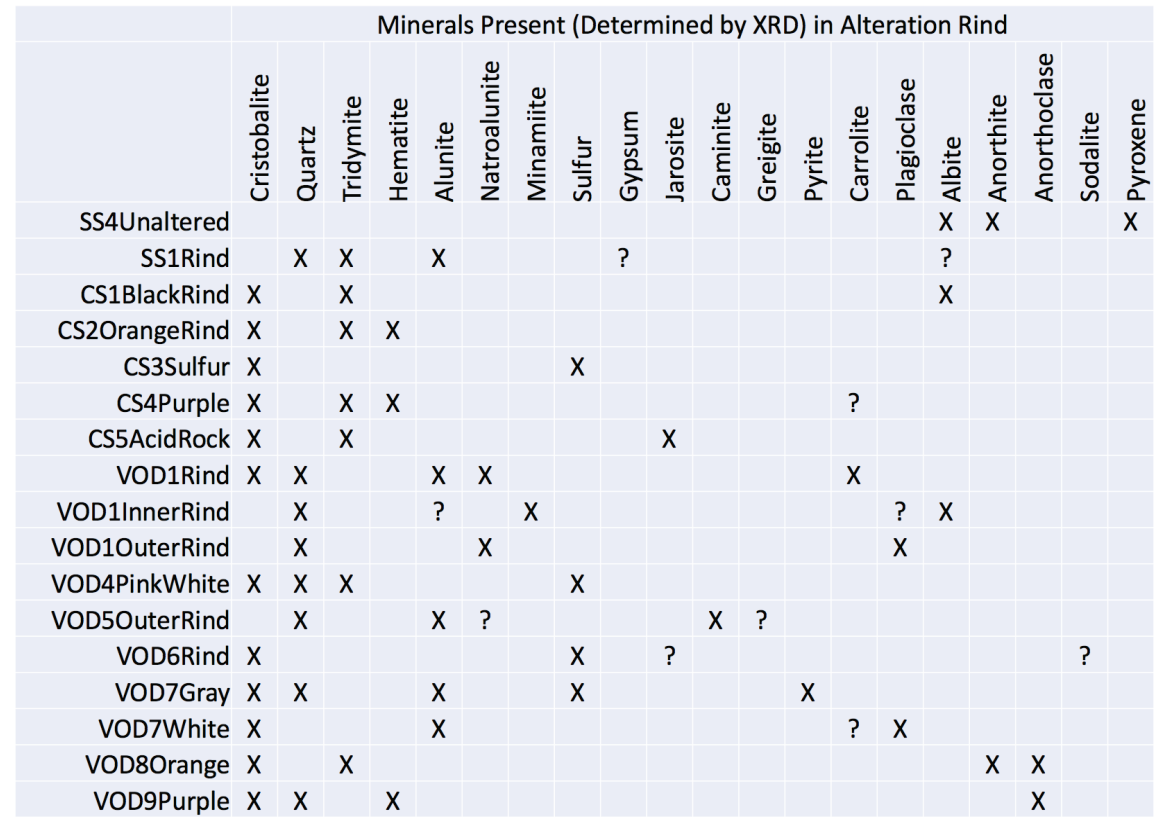

Fig. 2: Minerals detected in the XRD spectra are indicated as an " $X$ " in this table while minerals that were present in small amounts are indicated with a "?".

- Cristoballite

= Quartz

= Tridymite

- Hematite

- Alunite

= Natroalunite

Minamiite

= Sulfur

a Jarosite

Caminite

m Pyrite

= Carrollite

- Plagioclase

- Anorthoclase

- Pyroxene

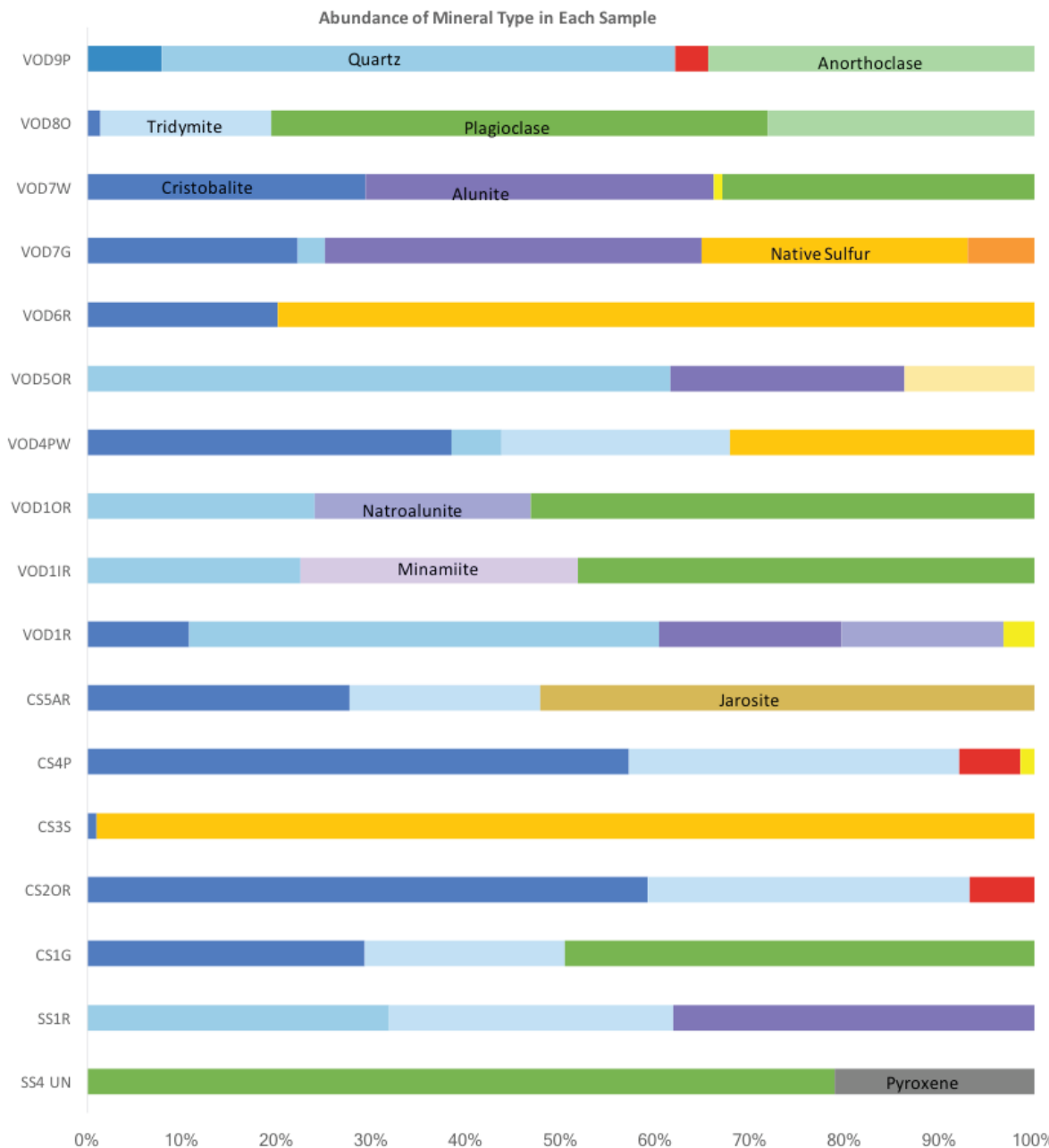

Fig. 3: Rietveld analysis yielded mineral abundances for each XRD sample. 
Cristobalite, sulfide, and sulfate minerals likely originate from hydrothermal vents, whereas fine grained iron oxides come from the alteration of Fe$\mathrm{Mg}$ minerals such as pyroxene. Native sulfur crystals observed in the field are attributed to precipitation of the sulfur present in fumarole gases (Mayer et al., 2017).

Africano et al. (2000) studied the Hsu volcano in Hokkaido, Japan. They found that cations from the original minerals had been completely leached, leaving only silica. The cations were found precipitated as secondary minerals in microcracks where fluid had entered and filled in the spaces. Similarly, in the Dominica samples, elemental maps (Fig. 4) show how silica polymorphs have replaced minerals such as plagioclase. Veins containing very fine grains of hematite and various sulfate minerals crosscut plagioclase and pyroxene crystals. Clay minerals, typical of argillic alteration, are often formed in hydrothermally active areas and are common in the andesites of the nearby island of Guadaloupe (Mas et al., 2006). Mayer et al. (2017) found the clay minerals montmorillonite and kaolinite in argillic samples from Valley of Desolation. However, no clay minerals have been detected in this study.

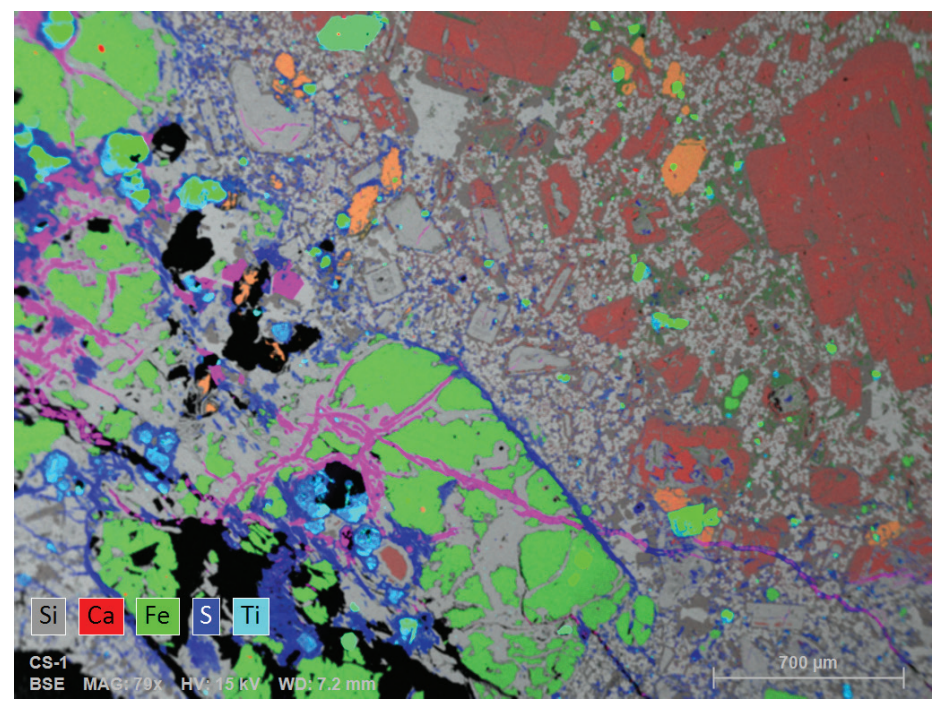

Fig. 4: An elemental map of a sample from the Cold Soufriere. False colors represent the elements present in the thin section. The alteration rind is located in the bottom left corner. Opx (green) is cross-cut by veins (blue, pink) of hematite and various sulfate minerals. Outlines of plagioclase phenocrysts are visible and have been replaced by silica polymorphs (gray) although a small amount of plagioclase remains in the center of the crystals.

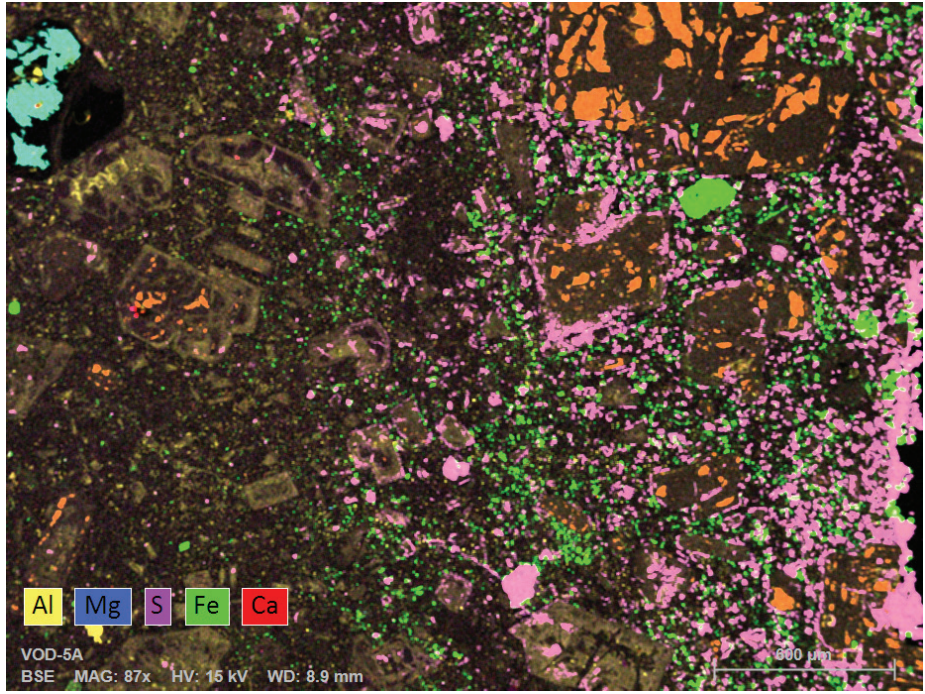

Fig. 5: An elemental map of a sample from the Valley of Desolation. The thick outer rim on the right shows the gradation in alteration from across the boundary from rock to rim. Very fine sulfide, sulfate and iron-titanium oxides minerals and alunite are found in this location. Plagioclase crystals have been replaced with silica.

Some minerals like gypsum, were found in the thin section using the SEM, but not detected by the XRD. A plausible explanation is that the XRD powders only contain minerals from the thinner sublimate on the outermost layer of the rock surface, excluding the core of the cobble, which may alter differently. Further work is necessary to characterize the varying degrees of alterations throughout the rock sample. Several rinds still contain plagioclase feldspar, suggesting that some of the original minerals have withstood the weathering conditions. Interestingly, of all samples that still contained feldspar, none contained sulfates (Fig 2). This indicates that these plagioclase-bearing rinds are less weathered. This is observed at all three sites. It is possible that the absence of sulfates is dependent on proximity to fumaroles and running water, as samples that are closer to the fluid discharge will have more exposure to alteration.

One sample from the Cold Soufriere includes a fine grained mix of oxide minerals consisting of iron, sulfur, and titanium. Minerals containing all three elements are rare, though this mineralogy has been discovered on Mars, which is known to have evidence of hydrothermal systems: the Spirit Rover discovered opaline silica, a hydrothermally derived silica polymorph, in the Gusev crater (Ruff et al., 2011). 
In the oxides on Dominica, there is a trend of iron concentration decreasing and sulfur concentration increasing moving from the core to outer edge of the rind. The amount of titanium, a relatively immobile element, remains constant. A possible explanation for this pattern is that the outer surface of the rind is more exposed to the sulfur bearing gases and fluids which cannot penetrate deeply into the core. Some of these oxides may have replaced ilmenite that was present in the host rock.

\section{CONCLUSIONS}

Both acidity and fluid availability in the environment caused differences in the degree of alteration of minerals, with those from the drier Sulfur Springs showing the least amount of alteration. Sulfur Springs is a hot and dry environment, Valley of Desolation is a hot and wet environment, and the Cold Soufriere is a wet and cold environment. The presence of water allowed for the movement of different elements and ions to enter and leave the rock, forming alteration minerals. Furthermore, acidity contributed to the degree of lithification of the rock regardless of temperature and may explain the alteration of the original mineralogy.

\section{ACKNOWLEDGEMENTS}

This material is based upon work supported by the Keck Geology Consortium and the National Science Foundation under Grant No. 1659322. A big thank you to the Commonwealth of Dominica for allowing this research to be conducted and to the mentors who advised me on this project: Holli Frey, Matt Manon, Erouscilla Joseph, Cam Davidson and Laura Waters.

\section{REFERENCES}

Africano, F., and Bernard, A., 2000, Acid alteration in the fumarolic environment of Usu volcano, Hokkaido, Japan: Journal of Volcanology and Geothermal Research, v. 97, p. 475-495, doi: 10.1016/s0377-0273(99)00162-6.

Aguilera, F., Layana, S., Rodríguez-Díaz, A., González, C., Cortés, J., and Inostroza, M., 2016, Hydrothermal alteration, fumarolic deposits and fluids from Lastarria Volcanic Complex: A multidisciplinary study: Andean Geology, v. 42, doi: 10.5027/andgeoV43n2-a02.

Onyeali, M. C., Joseph, E. P., and Frey, H. M., 2017, Investigating Volcanic-Hydrothermal Systems in Dominica, Lesser Antilles: Temporal Changes in the Chemical Composition of Hydrothermal Fluids for Volcanic Monitoring Using Geothermometers: Abstract 215815 presented at 2017 Fall Meeting, AGU, New Orleans, Louisiana, 11-15 December

Grazulis, S., Chateigner, D., Downs, R. T., Yokochi, A. T., Quiros, M., Lutterotti, L., Manakova, E., Butkus, J., Moeck, P. \& Le Bail, A., 2009, Crystallography Open Database - an open-access collection of crystal structures,. J. Appl. Cryst. 42, 726-729.

Joseph, E.P., Fournier, N., Lindsay, J.M., and Fischer, T.P., 2011, Gas and water geochemistry of geothermal systems in Dominica, Lesser Antilles island arc: Journal of Volcanology and Geothermal Research, v. 2016, p. 1-14.

Mas, A., Guisseau, D., Mas, P.P., Beaufort, D., Genter, A., Sanjuan, B., and Girard, J., 2006, Clay minerals related to the hydrothermal activity of the Bouillante geothermal field (Guadeloupe): Journal of Volcanology and Geothermal Research, v. 158 , p. $380-400$, doi: $10.1016 /$ j. jvolgeores.2006.07.010.

Mayer, K., Scheu, B., Yilmaz, T.I., Montanaro, C., Gilg, H.A., Rott, S., Joseph, E.P., and Dingwell, D.B., 2017, Phreatic activity and hydrothermal alteration in the Valley of Desolation, Dominica, Lesser Antilles: Bulletin of Volcanology, v. 79, doi: 10.1007/s00445-017-1166-0. 
Onyeali, M. C., Joseph, E. P., and Frey, H. M., 2017, Investigating Volcanic-Hydrothermal Systems in Dominica, Lesser Antilles: Temporal Changes in the Chemical Composition of Hydrothermal Fluids for Volcanic Monitoring Using Geothermometers: Abstract 215815 presented at 2017 Fall Meeting, AGU, New Orleans, Louisiana, 11-15 December

Ruff, S.W., Farmer, J.D., Calvin, W.M., Herkenhoff, K.E., Johnson, J.R., Morris, R.V., Rice, M.S., Arvidson, R.E., Bell, J.F., Christensen, P.R., and Squyres, S.W., 2011, Characteristics, distribution, origin, and significance of opaline silica observed by the Spirit rover in Gusev crater, Mars:

Journal of Geophysical Research, v. 116, doi: 10.1029/2010je003767.

Salaün, A., Villemant, B., Gérard, M., Komorowski, J.-C., and Michel, A., 2011, Hydrothermal alteration in andesitic volcanoes: Trace element redistribution in active and ancient hydrothermal systems of Guadeloupe (Lesser Antilles): Journal of Geochemical Exploration, v. 111, p. 59-83, doi: 10.1016/j.gexplo.2011.06.004 